\title{
Analisis Cerpen untuk Pembelajaran Sejarah Amerika
}

\author{
Sumini Theresia, Novita Dewi \\ novitadewi@usd.ac.id \\ Universitas Sanata Dharma
}

\begin{abstract}
This research is an analysis of three American short stories set in three different historical periods: "The Minister's Black Veil" by Nathaniel Hawthorne (The Puritans in New England), "Désirée's Baby" by Kate Chopin (Slavery in Louisiana before the Civil War), and Ken Liu's "The Paper Menagerie" (Interracial marriage in 1970s America). Using a close reading and content analysis method, this qualitative research examined the three short stories being the primary data and contextualized them with American history, each authors's short biography, and relevant texts that were treated as secondary data. The results shows that first, these short stories depict intolerance, identity crisis, and racism to various degrees. Secondly, religious and racial supremacy prevail throughout different historical times as imaginately revealed in each story. Thirdly, having been unfairly mistreated, women survived and their righteousness contributes to a new outlook about women's roles that official history often neglects. Finally, short stories provide meaningful enrichments in history teaching and they help foster critical thinking, empathy, as well as joys in learning.
\end{abstract}

Keywords: intolerance, identity crisis, racism, short story, American history

\begin{abstract}
Abstrak
Penelitian ini mengkaji tiga cerita pendek Amerika yang berlatar tiga zaman sejarah yang berbeda: "The Minister's Black Veil" oleh Nathaniel Hawthorne (Kaum Puritan di New England), "Désirée's Baby" oleh Kate Chopin (Perbudakan di Louisiana sebelum Perang Saudara), dan Ken Liu's "The Paper Menagerie" (Pernikahan antar ras di Amerika tahun 1970an). Penelitian kualitatif ini menganalisis ketiga cerpen yang menjadi data primer dan mengkontekstualisasikannya dengan sejarah Amerika, biografi pendek masing-masing pengarang, dan teks-teks yang relevan yang diperlakukan sebagai data sekunder. Metode yang dipakai adalah close reading yakni membaca secara cermat setiap teks, dan content analysis dengan cara menarik makna dari teks-teks yang dibaca melalui tahapan analisis, interpretasi, dan evaluasi. Hasil penelitian menunjukkan bahwa pertama, ketiga cerpen menggambarkan intoleransi, krisis identitas, dan rasisme dalam berbagai tingkatan. Kedua, supremasi agama dan warna kulit mendominasi sepanjang sejarah Amerika seperti yang diungkapkan secara imajinatif oleh setiap cerita. Ketiga, meskipun diperlakukan tidak adil, tokoh perempuan bertahan hidup. Sikap mereka memberikan pandangan baru tentang peran perempuan yang sering diabaikan oleh sejarah resmi. Sebagai simpulan, cerita pendek dapat diberikan sebagai materi pengayaan yang bermakna dalam pembelajaran sejarah untuk menggugah cara berpikir kritis, empati, serta kegembiraan dalam belajar.
\end{abstract}

Kata Kunci: intoleransi, krisis identitas, rasisme, cerpen, sejarah Amerika

\section{Pendahuluan}


Penelitian tentang pembelajaran sejarah baik di tingkat pendidikan dasar, menengah maupun perguruan tinggi di Indonesia menitikberatkan pada upaya untuk membuat pembelajar tertarik, termotivasi, dan pada gilirannya makin terbentuk pula karakter bangsa seperti yang diharapkan. Sejak dekade terakhir, pembelajaran sejarah berbasis multimedia dan teknologi menjadi topik kajian yang diminati (Awang et al., 2016; Printina, 2017; Putra, 2014; Ririmasse, 2017). Printina (2017), misalnya, meneliti efektivitas penggunaan sumber belajar digital lewat exelsa moodle dan komik Toondo untuk meningkatkan kreativitas belajar mahasiswa. Ada pula yang mengkaji sejarah lokal dan nilai-nilai kearifan lokal berikut peninggalan-peninggalan yang ada untuk menumbuhkan kepekaan sejarah (Ibrahim, 2018; Nu'man, 1988; Ufie, 2013).

Selain itu, tujuan, hakikat, dan tantangan dalam pembelajaran sejarah tetap menjadi topik yang diteliti dari waktu ke waktu seiring perkembangan zaman (Kartodirdjo, 1989; Senen \& Barnadib, 2000) dan terus-menerus direvitalisasi (Widja, 2018) serta diformulasikan (Sardiman, 2017). Disposisi ini berlanjut hingga pandemi COVID-19 melanda; dan tidak bisa tidak berpengaruh terhadap pembelajaran sejarah (Amboro, 2020; G. F. Kurniawan, 2020). Jika Amboro (2020) menyoroti pandemi ini sebagai peristiwa sejarah untuk dikaji secara kontekstual, bagi Ganda Febri Kurniawan (2019)Kurniawan (2020), pembelajaran sejarah secara daring menunjukkan kompleksitas tersendiri seraya menawarkan beberapa cara untuk menyiasatinya sehingga lebih menarik dan inovatif.

Kajian-kajian di atas sangat penting, tetapi pemakaian karya sastra sebagai sumber sejarah belum banyak mendapatkan perhatian, meskipun karya populer seperti komik sudah dimanfaatkan (Printina, 2017). Pembelajaran sejarah di Indonesia terkesan belum memanfaatkan karya sastra khususnya cerpen, padahal teks-teks sastra terbukti sangat efektif sebagai sumber belajar seperti yang telah dicontohkan dalam pembelajaran sejarah Amerika (Stoddard, 2012; VanSledright \& Kelly, 1998), Australia (Clark, 2004), dan Eropa (Einhaus, 2016; Hower, 2019).

Pada umumnya, karya-karya sastra yang dipakai sebagai "teks" sejarah dapat membantu mengembangkan pengetahuan konseptual dan empati sejarah. Karya imajinatif cukup bermanfaat untuk membantu pembelajar dalam memahami dan membuat pertimbangan atau penilaian atas peristiwa-peristiwa penting termasuk isuisu kontroversial dalam sejarah. Menurut seorang guru sejarah di sekolah menengah di Amerika, Wanda Miller, tidak ada yang membuat sejarah menjadi lebih "hidup" daripada membaca karya-karya sastra yang berkualitas tentang kehidupan yang dimaksudkan (1998). Meskipun fakta-fakta yang dipelajari dalam buku teks sejarah sangat penting, siswa sekolah yang diajarnya lebih mudah memahami periode waktu dan peristiwa tertentu melalui tokoh-tokoh sejarah dalam karya sastra anak, lanjut Miller sambil memberi sejumlah contoh karya yang lahir dari fakta sejarah Amerika Serikat setelah PD II, seperti Perang Korea, Pergerakan Hak-hak Sipil, Perlombaan senjata AS-Rusia, Perang Vietnam, dan sebagainya.

Penelitian ini bertujuan menganalisis cerita-cerita pendek dalam khasanah sastra Amerika dalam pembelajaran Sejarah Amerika di tingkat universitas. Mengapa cerita pendek? Banyak penelitian telah menunjukkan keberhasilan cara ini; dan telah 
terdokumentasi melalui sejumlah skripsi, tesis, disertasi, dan karya ilmiah lainnya (VanSledright \& Kelly, 1998; Zollinger, 1851; ZS, 2003; Zubaidah, 2010). Kajian tentang efek positif membaca fiksi sejarah terhadap perkembangan, pemahaman, dan empati pembelajar juga telah banyak didokumentasikan dalam sejumlah penelitian (Dewi, 2013; Sanchez \& Mills, 2005; Thornton \& Cruz, 2013). Sebagian besar dampak yang ditimbulkan terkait dengan aspek sejarah manusia. Mahasiswa mengembangkan pemahaman tentang kondisi di masa lalu dan menyadari bahwa semua makhluk terhubung satu dengan yang lainnya. Novel, misalnya, memancing pembaca untuk berpikir, merasakan, dan membayangkan peran tokoh-tokoh di masa silam.

Kajian-kajian terdahulu seperti dicontohkan di atas secara umum menegaskan perlunya pendidikan karakter disampaikan semenarik mungkin dalam mengajarkan sejarah melalui kisah-kisah khayali yang berbasis peristiwa nyata di masa lampau untuk dijadikan pembelajaran sekaligus pedoman (Sanchez \& Mills, 2005; Youngs, 2012). Melalui teks-teks sastra, mahasiswa akan mendapatkan pemahaman yang lebih baik tentang kronologi peristiwa dan tentang bagaimana sejarah manusia berkembang seiring waktu(Thornton \& Cruz, 2013). Dengan cara ini mereka juga belajar mengenal pelbagai bias maupun purbasangka dan beragam pilihan sudut pandang serta caracara menyikapi perbedaan lewat tokoh-tokoh fiksi yang berbasis sejarah Contoh paling terkenal adalah novel Gubug Paman Tom karya Harriet Beecher Stowe yang memicu dihapuskannya sistem perbudakan di Amerika Serikat.

Selain fungsi strategis karya sastra sebagai pendukung kajian sejarah, pembelajaran daring yang telah berjalan sejak merebaknya pandemi Covid-19 memungkinkan penambahan bahan atau sumber belajar seluas-luasnya, termasuk di dalamnya materi pengayaan berupa cerita-cerita pendek yang relevan dengan topik sejarah yang dipelajari. Pembelajaran sejarah yang kritis, kreatif, dan kontekstual semacam ini yang menjadikan penelitian tentang cerpen-cerpen Amerika ini menjadi penting.

Berdasarkan latar belakang tersebut, penelitian ini akan menjawab pertanyaan berikut: Analisis karya sastra Amerika berupa cerpen seperti apa yang dapat dimanfaatkan untuk diajarkan secara kritis membangun empati sejarah ketika berhadapan dengan realitas dunia yang kelam seperti kemunafikan, rasisme, dan intoleransi? Kajian ini menawarkan gagasan bahwa cerpen dapat dimanfaatkan untuk meningkatkan keterampilan berpikir kritis dengan cara mendorong mahasiswa membuat pembedaan antara fakta dan fiksi, kebenaran dan kebohongan (hoaks), dan sebagainya. Mahasiswa dapat melakukan pembacaan kritis dengan cara menganalisis, menginterpretasi, dan mengevaluasi teks-teks sastra berlatar belakang sejarah. Fiksi sejarah dapat menawarkan kesempatan dan cara praktis untuk membantu mahasiswa melihat dengan berbagai perspektif. Selain dapat membantu mahasiswa dalam memahami pola sejarah dan analogi politik suatu bangsa, tulisan kreatif semisal cerpen sekaligus memperkenalkan mahasiswa pada historiografi, yakni bagaimana sejarah ditulis dan dipelajari. Dinamika dan perubahan politik yang begitu cepat di Amerika akhir-akhir ini, misalnya, barangkali bisa ditelisik sebab-musababnya dari sejarah masa lalu bangsa ini yang terekam secara sastrawi. 


\section{Metode Penelitian}

Penelitian ini merupakan sebuah kajian tekstual, deskriptif-kualitatif. Pertamatama, dilakukan studi pustaka yang ekstensif, yakni mendata karya sastra Amerika berupa cerpen yang bertemakan sejarah bangsa tersebut. Data diperoleh lewat studi terdahulu atas sejumlah karya yang ada melalui buku-buku teks, artikel jurnal ilmiah mutakhir, karya tulis/skripsi/tesis/disertasi, dan sumber-sumber relevan lainnya. Setelah "data direktori" ini diperoleh, ditentukanlah 3 (tiga) cerpen untuk dicermati lebih lanjut dan dijadikan data primer. Ketiga cerpen dipilih karena mewakili tiga zaman yang berbeda dalam sejarah Amerika. Cerpen-cerpen ini mewakili tonggak sejarah perbenturan budaya dan bentrokan antar etnis dari masa ke masa. Imajinasi konflik secara sastrawi diharapkan membantu mahasiswa dalam menyikapi secara empatik dan bijaksana berbagai perpecahan dan keterbukaan dalam masyarakat modern yang terjadi akhir-akhir ini. Dengan bantuan data sekunder (artikel, jurnal ilmiah, sinopsis, tinjauan buku di koran ataupun majalah, dan lainnya), dilakukan pembacaan yang lebih intensif dengan memperhatikan kontekstualitas ketiga cerpen dengan peristiwa- peristiwa penting dalam sejarah Amerika. Interpretasi dan kontekstualisasi teks-teks ini mengikuti metode George (2008) yang lazim digunakan dalam kajian pustaka. Selanjutnya, diterapkan teknik membaca cermat (close reading) dan analisis konten dengan cara melakukan pembacaan kritis atas ketiga cerpen. Tentang analisis konten, Huckin (2004) berpendapat bahwa "titik awal yang logis untuk menganalisis teks adalah mempertimbangkan makna teks. Semua teks berbicara tentang sesuatu hal (memiliki konten)." Dengan demikian, cara paling jitu untuk memperhitungkan makna adalah melalui analisis isi. Sedangkan membaca kritis adalah proses menganalisis, menafsirkan, dan mengevaluasi. Metode membaca cermat dan berpikir kritis dari Paul \& Elder (2004) diaplikasikan di sini. Dari pembacaan kritis ini di tentukanlah tiga tema, yaitu kemunafikan, rasisme, dan intoleransi. Teks dan analisisnya kelak akan dapat digunakan sebagai bahan pembelajaran dalam perkuliahan Sejarah Amerika.

\section{Hasil dan Pembahasan Penelitian}

Pertama-tama disajikan tabel data berikut menampilkan tiga judul cerpen dan konteks sejarah Amerika yang melatarbelakangi masing-masing cerpen untuk memudahkan penjelasan.
No Judul Cerpen
Konteks Historis
1 "The Minister's Black Veil"
Perpindahan Kaum Puritan dari Inggris ke Amerika untuk mencari kebebasan beragama.
2 "Désirée's Baby"
Konflik budaya imigran Perancis yang dipengaruhi oleh perbudakan di Louisiana, Amerika Serikat.



politik dagang dan migrasi global.

\section{Tabel 1. Cerpen dan Konteks Historis}

Tiga pilar historis masyarakat Amerika yang berbeda zaman mewakili ketiga cerpen yang diteliti. Pertama, setelah Kaum Peziarah dari Inggris menetap dan memulai kehidupan baru di Jamestown, New England pada awal abad ke-17, Kaum Puritan yang tidak puas pada Gereja Anglikan dan menginginkan pemurnian ajaran gereja ikut menyusul pada tahun 1626 dan bermukim di Salem, dekat Plymouth, Massachusetts. Kedua, perbudakan di negara bagian Louisiana makin kokoh setelah akuisisi wilayah tersebut yang dibeli dari Perancis pada tahun 1803 - hasil negosiasi Napoleon yang butuh biaya untuk perang dan Presiden Thomas Jefferson yang berambisi memperluas wilayah Amerika Serikat. Ketiga, industri pengantin pesanan dari Asia, yang sudah berlangsung sejak tahun 1800 di perbatasan Amerika, makin marak setelah Undang-Undang Hak Sipil 1964, disahkan meskipun nasib kaum perempuan dan imigran tidak serta-merta membaik. Dengan ketiga latar belakang sejarah tersebut, hasil pembacaan ketiga cerpen menguak terjadinya kemunafikan, rasisme, dan intoleransi dalam sejarah Amerika dari waktu ke waktu seperti dijelaskan berikut ini.

\section{Pertobatan di Tengah Kemunafikan}

“The Minister's Black Veil" ditulis oleh Nathaniel Hawthorne pada tahun 1836. Di awal karirnya, Hawthorne kerap menulis tentang pengaruh kejahatan terhadap kepribadian seseorang dan komunitasnya (Kaplan, 2018; Kopley, 2012; Strong, 2017). Topik kemunafikan dan kebutaan moral menjadi ciri pengarang Amerika abad kesembilan belas yang hidup seperti seorang pertapa di Salem, Massachusetts ini.

Berlatar di kota kecil Milford, Connecticut, "The Minister's Black Veil" menceritakan tentang Pendeta Hooper yang mengejutkan jemaatnya ketika tampil di kebaktian Minggu dengan mengenakan kerudung hitam yang menutupi hampir seluruh wajahnya. Pada acara pemakaman seorang gadis muda, kerudung hitam itu tetap dikenakan oleh Pendeta Hooper. Jemaat curiga akan adanya dosa yang dirahasiakan ketika gadis itu masih hidup, meskipun tuduhan ini tidak pernah terbukti. Misteri kerudung hitam membuat Hooper dijauhi oleh jemaat dan komunitasnya. Elizabeth, tunangan Hooper akhirnya memutuskan hubungan karena pendeta itu menolak melepaskan kerudungnya maupun menerangkan alasan yang sesungguhnya. Pendeta ini masih dikenal sebagai pria yang ramah, lembut, dan penuh kasih, tetapi tidak dicintai, hanya ditakuti. Hooper tidak pernah diundang pada acaraacara gembira. Namun pada saat ada orang berdosa sedang sekarat, pendeta ini dipanggil untuk membantu melepaskan jiwa-jiwa yang tersiksa. Hooper hidup tanpa cela dan berumur panjang, bahkan lebih tua dari kebanyakan jemaat yang dilayaninya. 
Elizabeth, mantan tunangan yang tetap melajang, membuktikan diri sebagai teman setia Hooper yang merawat dan mendukungnya hingga pendeta itu menemui ajalnya. Saat dia sekarat, Pendeta muda Clark dari kota terdekat Westbury meminta Hooper untuk melepas kerudung hitamnya. Hooper menolak seraya menjelaskan bahwa ia memakai kerudung hitam sebagai simbol lahiriah timbunan dosa-dosanya. Pendeta tua itu mengklaim telah melihat kerudung hitam di wajah setiap orang yang dia temui. Semua orang mengenakan selubung rahasia penutup sisi gelap kehidupan, katanya, tetapi tidak kasat mata seperti kerudung hitam yang terus dikenakannya hingga ke liang kubur.

Cerpen ini sarat dengan latar belakang sejarah Puritanisme di Amerika. Pendeta Hooper berusaha menjalankan sungguh-sungguh salah satu doktrin Puritanisme, yakni semua orang lahir dengan dosa asal yang berasal dari Adam. Istilah "Puritan" dalam konteks Sejarah Amerika dipakai untuk menyebut kaum agamawan yang meyakini bahwa tidak ada yang lebih penting dalam hidup selain keyakinan religius seseorang (Leise, 2017; Packer, 1994). Keyakinan ini mendikte bagaimana seseorang mengubah dirinya di dunia ini dengan cara bekerja keras dan tekun beribadah untuk meraih kesuksesan. Karena etos kerja adalah keutamaan, mereka yang gagal, di mata Kaum Puritan, adalah bukti hukuman Tuhan (Kang, 2009; Luzer, 2013; Ryken, 2011). Banyak nilai Puritan yang tidak relevan lagi saat ini, tetapi terlepas baik atau buruknya, nilai-nilai itu telah membentuk identitas Amerika. Pada tahun 1989, misalnya, Ronald Reagan mengutip kata-kata gubernur Koloni Teluk Massachusetts John Winthrop, yang membayangkan koloni itu sebagai "kota di atas bukit" untuk ditiru oleh bangsa-bangsa di masa depan (Leise, 2017). Meskipun pidato Reagan yang meminjam retorika khas Winthrop menjadi lambang idealisme Amerika, bagi kebanyakan orang Amerika, Puritanisme dan New England bukanlah identitas asli Amerika Serikat, untuk tidak menyebut palsu atau dibuat-buat demi penampilan luar semata.

Kaum Puritan di Connecticut yang menjadi konteks cerpen Hawthorne acapkali digambarkan sebagai orang-orang yang taat dalam beragama tetapi cepat menghakimi. Dalam karya terbesarnya The Scarlet Letter, misalnya, Hawthorne menampilkan masyarakat yang soleh tetapi sekaligus munafik dan tidak segan-segan menghukum atau setidaknya mencampakkan mereka yang dipandang telah berbuat dosa. Tokoh utama novel yang ditulis pada tahun 1850 ini, Hester Prynne, melahirkan anak di luar pernikahan. Ia dihukum berat dengan mengenakan baju bersulamkan huruf A berwarna merah di bagian dada singkatan kata "adultery" atau perzinahan. Prynne menjalani sanksi sosial itu tanpa melawan. Ia tetap menutup mulut tentang ayah bayi yang dikandungnya yang ternyata seorang tokoh agama yang terpandang.

Seperti Hester Prynne yang terus hidup baik, rajin bekerja, dan merawat anaknya dengan kasih sayang sebagai tanda pertobatan, Pendeta Hooper menjalankan panggilan hidupnya dengan tak bercela meskipun jemaat tidak menyukainya bahkan takut kepadanya. Gambaran penulisnya tentang tokoh ini jelas: "Di antara semua pengaruh buruk [Hooper], cadar hitam memberikan efek yang diinginkan untuk membuat pemakainya menjadi pendeta yang sangat efisien" (Hawthorne, 2004). 
Pendeta ini berperilaku baik, tetapi jemaat tetap berspekulasi tentang kehidupan pribadinya. Pengalaman ini sama dengan realitas masyarakat tempat tinggal Hester Prynne yang terus-menerus melakukan perundungan atas perempuan itu. Jika baju berlabel A merah dikenakan secara paksa kepada Prynne, kerudung hitam dipakai Hooper atas kehendaknya sendiri. Keduanya adalah simbol dosa dan pertobatan individu yang tidak diterima dengan baik oleh masyarakat yang menganggap diri sendiri murni, bersih, dan tak bercacat sedikitpun.

Hawthorne menampilkan gambaran masyarakat yang hipokrit, tidak toleran, dan sangat gemar mendakwa salah terhadap mereka yang dipandang lemah dan tak berdaya. Sejarah menunjukkan intoleransi Kaum Puritan terhadap Kaum Quaker (Hamm, 2016; Pestana, 1993). Karena berpandangan berbeda dengan Kaum Puritan, mereka ditindas dan tidak boleh memasuki wilayah Kaum Puritan. Catatan sejarah yang paling kelam terjadi pada 1692, yakni Salem Witch Trials. Berpuluh-puluh orang tidak bersalah dihukum gantung tanpa diadili karena tidak mau mengakui tuduhan bahwa mereka mempraktikkan ilmu sihir. Nenek moyang Nathaniel Hawthorne adalah salah satu jaksa dalam peradilan yang mengerikan ini.

Meskipun cerpen "The Minister's Black Veil” terbuka pada pelbagai penafsiran, kisah ini mengikuti tema dan alur penceritaan khas Hawthorne, yakni kritik atas peradaban yang sarat dengan syak, purba sangka, dan berujung pada intoleransi dan kekerasan. Seperti Edgar Allan Poe, Herman Melville, dan penulis-penulis zaman Dark Romanticism lainnya, Nathaniel Hawthorne menuliskan kisah-kisah kemunafikan atau kegagalan institusi agama dan budaya yang justru mengekalkan bukannya memberantas hal-hal yang dianggap dosa atau tak bermoral yang hendak secara paksa dihentikan itu (Kopley, 2012; Muse, 2014; Strong, 2017).

Sebagai perbandingan, Rahman dan Jackson (2016) memakai cerpen "The Minister's Black Veil" dan sebuah cerpen berjudul "Fajr". Cerpen "Fajr" yang bercerita tentang persahabatan antara siswa Yahudi dan Muslim) dibaca oleh dua kelompok siswa masing-masing dari sekolah negeri dan sekolah Islam di Queens, Amerika Serikat. Selain itu kedua peneliti juga membuat survei yang sama pada sejumlah calon guru melalui sebuah lokakarya dengan memberikan cerpen “The Minister's Black Veil". Hasilnya cukup menggembirakan: masing-masing kelompok mulai memahami bahwa ketakutan terhadap Sang Liyan terjadi karena ketidaktahuan semata sehingga mereka merasa terancam satu sama lain. Dari contoh pemahaman lintas-iman dan multikultural ini, terbukti bahwa pembelajar dari pelbagai kelompok yang berbeda tidak lagi merasa terusik atau tidak nyaman dengan penampilan kelompok lain, dalam hal ini, pemakaian hijab (dalam "Fajr") dan cadar hitam (dalam "The Minister 's Black Veil") mempunyai latar budaya dan sejarah yang saling memperkaya. Kontekstualisasi karya sastra dan peristiwa sejarah semacam ini dapat membantu pembelajaran Sejarah Amerika menjadi lebih menarik dan penuh makna. Tanpa menggurui, sastra berfungsi sebagai kontemplasi sekaligus pengingat agar kita terus belajar dari kesalahan dalam sejarah untuk masa depan yang lebih baik.

\section{Perbudakan sebagai Pemicu Rasisme}


Ditulis pada 1893 oleh Kate Chopin, "Désirée's Baby" mengisahkan tragedi kawin campur di negara bagian Louisiana selama periode antebellum. Désirée adalah anak angkat Monsieur dan Madame Valmondé, bangsawan Kreol Prancis di Louisiana, yang ditinggalkan orang tuanya saat masih bayi pada masa sebelum Perang Saudara. Setelah dewasa, perempuan rupawan ini menikah dengan Armand Aubigny, putra keluarga Kreol Prancis yang juga kaya raya dan terhormat. Ketika bayi mereka lahir, orang terkejut karena warna kulitnya gelap menyerupai keturunan Afrika. Armand mencemooh, bersikap dingin, dan membiarkan Désirée pergi. Ibu muda itu membawa bayinya menuju ke rawa dan tidak pernah terlihat lagi. Armand membakar barangbarang milik Désirée, termasuk semua surat sejak mereka pacaran. Di antara bundelan surat-surat, ditemukan sebuah surat dari Madame Aubigny (ibu Armand) di Prancis yang memohon agar suaminya merahasiakan fakta tentang nenek moyang Armand yang berkulit hitam.

Konteks sejarah cerpen ini adalah perbudakan di wilayah Selatan Amerika, seperti sejumlah karya Chopin lain yang mengharumkan namanya sebagai penulis feminis karena secara kritis menyoroti bias gender dan ketimpangan sosial. Chopin mengambil latar belakang kehidupan sosial masyarakat Louisiana yang berlapis-lapis. Penulis yang bernama asli Katherine O'Flaherty ini hidup di zaman ketika Amerika tergagap karena efek industrialisasi, urbanisasi, dan imigrasi. Masyarakat menjadi semakin bertingkat secara budaya, ekonomi, dan politik, serta berakhir dengan Perang Saudara. Ternyata perang dan Rekonstruksi juga tidak memuaskan, disusul dengan krisis finansial yang parah pada tahun 1873. Sejarah perbudakan di Amerika Serikat dapat ditelusuri terutama di negara bagian "Ujung Selatan" seperti Mississippi dan Louisiana, di mana perkebunan kapas dan tebu pernah membutuhkan budak dalam jumlah besar untuk menopang perekonomian (Cook, 2016).

Garis keturunan, reputasi, dan status keluarga sangat penting dalam budaya perkebunan di Amerika bagian Selatan sebelum Perang Saudara. Pernikahan, persahabatan, dan relasi lainnya amat dipengaruhi oleh stratifikasi sosial dan kekuasaan. Asal-usul Désirée tidak jelas karena Valmondé, ayah angkat Désirée menemukan bayi cantik itu "di antara dua pilar batu" di pagar depan rumahnya (Chopin, 2014). Hal ini dijadikan bukti oleh Armand sebagai penyebab gelapnya warna kulit anak mereka. Hirarki sosial di Louisiana pada pertengahan abad ke-19 menempatkan orang kulit putih pemilik tanah di tingkat sosial teratas dan yang memiliki darah budak berkulit hitam di paling bawah. Kedatangan bangsa AngloAmerika di negara bagian Louisiana menghasilkan undang-undang yang lebih ketat dalam mengatur perbudakan. Ketidakadilan dan penganiayaan baik fisik maupun mental terhadap budak kulit berwarna meninggalkan jejak sejarah yang tidak mungkin dihapus (Hirsch, A. R., \& Bell, 1998).

Orang Amerika di wilayah Selatan pada umumnya yang senang bernostalgia tentang masa lalu yang tampak lebih stabil dan tidak rumit. Namun Kate Chopin tidak demikian. Ia bernarasi dengan gaya khas pengarang zaman Realisme. Gaya penulisannya lugas dan tidak bermain-main dengan kata-kata indah untuk menutupi kenyataan. Meskipun pengarang yang menikah dengan pebisnis Oscar Chopin ini 
masuk dalam golongan masyarakat berstatus sosial tinggi di Louisiana waktu itu, ia tidak segan-segan menulis apa adanya tentang realitas kaumnya. Tokoh Armand ditampilkan sebagai pribadi yang umum dijumpai pada anak orang kaya seperti misalnya pemilik perkebunan luas. Armand berperangai kasar dan kerap menyiksa budak-budaknya.

Cruz \& Duplass (2009) memakai cerpen “Désirée's Baby" di kelas sejarah untuk menerangkan tentang sejarah ras di Amerika Serikat. Keberhasilan kelas mereka antara lain disebabkan oleh pilihan teks itu sendiri: tidak terlalu panjang, penggambaran masyarakat perkebunan dan istilah-istilah Kreol Perancis yang menarik bagi siswa, dan akhir cerita yang dramatis jika dipentaskan (Thornton \& Cruz, 2013).

Imajinasi perbudakan dan rasisme serta implikasinya menjadi lebih nyata dalam pembelajaran Sejarah Amerika ketika cerpen seperti "Désirée's Baby" ini diberikan sebagai bacaan pengayaan. Kisah tentang konflik yang dipicu oleh arogansi budaya dan xenophobia ini membantu membuka kesadaran pembelajar untuk menghargai perbedaan, memperjuangkan keadilan, menjunjung martabat manusia, dan berbagai keutamaan lainnya ketika mempelajari sejarah suatu bangsa. Kita dapat belajar mengapa perbudakan modern tetap berlangsung hingga kini seperti perdagangan manusia, misalnya. Belajar dari tokoh-tokoh di masa silam yang dihadirkan dalam karya sastra dapat membantu menumbuhkan kepekaan dan empati sejarah agar kesalahan yang sama tidak diulang sekaligus mencari cara-cara baru untuk memperbaikinya (Stambuk, 1999; Stoddard, 2012). Untuk menyebut sebuah contoh lagi, disertasi Quong (2019) menunjukkan bahwa siswa kelas yang hanya mempelajari sejarah tidak memiliki empati histori setinggi siswa dari kelas pembanding yang belajar sejarah dan sastra Inggris yang antara lain memakai cerpen "Désirée's Baby" sebagai salah satu teks yang diajarkan.

\section{Intoleransi dan Identitas Diri}

“The Paper Menagerie" karya penulis fiksi sains kontemporer Amerika Ken Liu bercerita tentang Jack, pria Amerika berdarah Cina yang mengalami krisis identitas. Berlatar di negara bagian Connecticut, cerita dibuka dengan Jack kecil yang terlihat gembira bermain-main dengan origami berbentuk macan buatan ibunya. Macan dari kertas itu seakan "hidup" saat perempuan asal Cina itu meniupkan udara ke dalamnya. Jack yang mewarisi mata sipit ibunya tumbuh menjadi remaja dan berusaha keras menyesuaikan diri dengan teman-teman Amerika yang kerap menganggapnya berbeda. Lambat laun Jack tahu ibunya menikah dengan ayahnya melalui sebuah katalog pengantin pesanan. Merasa kecewa dan malu, Jack mulai mengabaikan origami dan ibunya. Ibu Jack berusaha belajar bahasa Inggris dan budaya Amerika untuk menyenangkan anaknya, namun Jack justru makin jarang berbicara kepada ibunya dan berusaha untuk menjadi seorang Amerika tulen. Hubungan kedua nya semakin renggang; dan setelah menyelesaikan studi Jack bekerja di negara bagian lain. Jack kembali saat ibunya sakit parah dan sebelum meninggal 
berpesan agar Jack membuka sebuah kotak sepatu yang selama ini disimpan untuk dibuka pada waktunya. Ayah Jack menua dengan cepat sepeninggal istrinya dan rumah mereka menjadi terlalu besar untuk dihuni seorang diri. Saat mengemasi barang-barang untuk pindahan, Jack dan Susan, pacar Amerikanya, menemukan kotak sepatu yang berisi origami macan kesukaan Jack di masa kecil dan sepucuk surat dari ibunya yang ditulis dalam bahasa Cina. Jack minta tolong seseorang untuk membaca surat itu. Banyak kata 'ai' (cinta) ditemukan di dalamnya. Ibunya bercerita tentang masa kecilnya yang menyedihkan di Cina setelah kedua orangtuanya meninggal pada zaman Revolusi Kebudayaan. Anak yatim piatu ini lalu pergi ke Hongkong untuk menemui pamannya. Ia bekerja serabutan di Hongkong sampai ia dinikahi oleh seorang pria Amerika, yaitu ayah Jack, yang mencari jodoh lewat katalog. Dikatakan dalam surat itu meski Jack menghindari cinta ibunya, perempuan yang hampir sepanjang hidup menderita itu tidak pernah berhenti mencintai anak semata wayangnya yang telah memberinya sedikit kebahagiaan. Jack akhirnya menerima siapa dirinya dan tidak lagi malu dengan identitasnya.

Cerpen ini merupakan salah satu dari kumpulan cerpen berjudul The Paper Menagerie and Other Stories yang terbit tahun 2011. Pada 2012, Ken Liu memenangkan tiga penghargaan sekaligus, Hugo Award, Nebula Award, dan World Fantasy Award untuk buku ini. Isu rasisme dan krisis identitas yang diangkat oleh Liu gayut dengan latar tempat dan waktu untuk cerpennya, yakni awal 1970-an setelah diberlakukannya Undang-Undang Hak Sipil tahun 1964. Undang-undang ini mengatur hak sipil dan ketenagakerjaan di Amerika Serikat yang melarang diskriminasi berdasarkan ras, warna kulit, agama, jenis kelamin, asal kebangsaan, sampai orientasi seksual dan identitas gender (Gavins, 2016). Demikian pula halnya dengan latar tempat, yakni Connecticut. Negara bagian Selatan ini memiliki sejarah perbudakan yang membayangi masyarakatnya. Baru pada tahun 2007, Senat Amerika Serikat yang mewakili Connecticut bersama enam negara bagian lainnya meminta maaf kepada warga Afrika-Amerika tentang peran wilayah tersebut dalam melanggengkan perbudakan melalui Perdagangan Budak Eropa di masa lampau yang telah meninggalkan luka mendalam (Davis, 2014). Gambaran suasana di Connecticut di zaman modern diimajinasikan oleh Liu lewat tokoh Jack yang mengalami diskriminasi oleh teman sepermainan dan para tetangga yang kurang ramah pada pendatang.

Suatu hari dua orang tetangga datang menyambangi keluarga Jack. Mereka heran mengapa ayah Jack menikahi perempuan asing yang tidak bisa berbahasa Inggris. Kedua tamu berbisik satu dengan yang lain tentang Jack: “Blasteran yang tidak beres. Anak itu tampak belum selesai. Mata sipit, wajah putih. Monster kecil." Bahkan ketika Jack menjawab pertanyaan dengan lancer 
dalam bahasa Inggris, salah satu dari mereka berkomentar, "Kedengarannya tidak terlalu Cina." (Liu, 2011, p. 30). Dari sini Jack merasa perlu melakukan asimilasi dengan budaya Amerika sepenuhnya dan meninggalkan warisan budaya ibunya yang dianggap memalukan dan tidak dapat diterima di lingkungannya.

Ketika Jack sedang menikmati bermain-main dengan origami macannya, Mark anak tetangga datang membawa mainan Star Wars. Tanpa sengaja figure "Obi Wan Kenobi Lightsaber" milik Mark jatuh terhempas oleh sambaran macan Jack dan kedua anak laki-laki itu bertengkar. Mark marah dan menuntut ganti. Anak ini berkomentar bahwa mainannya lebih mahal dari uang yang dibayarkan oleh ayah Jack untuk membeli ibunya dan membawanya pulang ke Amerika dari Hong Kong. Kenangan pahit masa kecil dan perlakuan rasis yang diterima Jack membuatnya makin membenci identitas dirinya yang hibrid.

Nampaknya Liu menyoroti fenomena industri "Mail-Order Brides" atau pengantin pesanan (Liu, 2011) yang makin marak belakangan ini. Perantara pernikahan internasional selalu mengklaim bahwa layanan mereka memfasilitasi hubungan jangka panjang antara pria dan wanita di seluruh penjuru dunia. Namun, oleh ahli hukum, pembela hak asasi manusia, kaum feminis, dan cendekiawan, hubungan "asmara"semacam itu bersifat eksploitatif dan dapat digugat dalam kaitannya dengan perdagangan manusia (Yakushko \& Rajan, 2017). Cerpen Liu dapat dipakai sebagai pengayaan dalam pembelajaran tentang perundungan terhadap perempuan dan kaum minoritas yang terjadi di sepanjang sejarah Amerika Serikat dengan tingkat yang berbeda-beda.

Rasisme yang diinternalisasi oleh tokoh Jack menyebabkan kebencian terhadap dirinya sendiri. Jack berharap menjadi kulit putih dan "normal". Liu menggambarkan penolakan warisan ke-Asia-an yang menjadi hal yang jamak dalam masyarakat yang percaya akan adanya "white supremacy", keunggulan ras kulit putih. Jika akhir-akhir ini masyarakat Amerika Serikat kembali terbelah dan tercerai-berai pasca pemerintahan Donald Trump, benih-benih rasisme dan supremasi kulit putih sudah tertanam sejak lama.

Judul cerpen "The Paper Menagerie" juga bermakna simbolis. Koleksi origami Jack terdiri-dari berbagai binatang seperti macan, ikan hiu, kambing, kerbau, dan sebagainya. Keanekaragaman ini sejalan dengan identitas dan semangat multikulturalisme Amerika Serikat yang diidamkan oleh pendiri bangsa. Istilah-istilah seperti "melting pot", "salad bowl", dan "e pluribum unum" yang tertera pada lambang negara dan didengung-dengungkan seakan menjadi jargon belaka. Semboyan persatuan dalam perbedaan ini menjadi hampa dengan maraknya kerusuhan bernuansa SARA akhir-akhir ini. 
Pembelajaran sejarah yang transformatif dapat memanfaatkan cerpen semacam “The Paper Menagerie" ini untuk menimbulkan empati. Cerpen Ken Liu dapat dimanfaatkan untuk membuka kesadaran agar kita belajar dari sejarah masa lalu untuk menghadapi masa kini dan mengawal masa depan. Sebagai karya fiksi yang relatif baru, "The Paper Menagerie" kerap dibahas dalam telaah fiksi sains (Sohn, 2019; Song, 2013) dan sastra multikulturalisme (Gonzalez, 2017). Akan tetapi, nilai transformatif cerpen ini menjadikannya penting seperti dalam kajian Dervin \& Jacobsson (2021) tentang pendidikan kritis interkulturalitas. Dengan demikian hasil analisis cerpen ini diharapkan dapat memperkaya pemahaman dan empati historis mahasiswa jurusan Sejarah dan studi sosial lainnya.

\section{Simpulan}

Penelitian ini telah menunjukkan bahwa hasil analisis ketiga cerpen, yakni "The Minister's Black Veil", "Désirée's Baby", dan "The Paper Menagerie" dari khasanah sastra Amerika dapat membantu mahasiswa memperoleh pemahaman yang empatik tentang kronologi dan perkembangan sejarah Amerika seiring waktu. Melalui pembacaan kritis, yakhni menganalisis, menafsirkan, dan mengevaluasi cerpen-cerpen tersebut mahasiswa dapat dilatih membuat pilihan guna menyikapi pelbagai perbedaan, bias, dan prasangka yang terjadi dalam dunia nyata seiring perubahan zaman.

Telah ditunjukkan dalam penelitian ini bahwa, pertama, intoleransi selalu mewarnai setiap fase peradaban. Intoleransi terhadap individu atau kelompok (keluarga) yang berbeda dengan kelompok mayoritas diimajinasikan dalam cerpen Nathaniel Hawthorne dan Ken Liu. Jemaat tidak menyukai gaya Pendeta Hooper yang dianggap aneh, tidak wajar, dan bahkan menakutkan di mata mereka. Jack yang berdarah campuran Cina-Amerika selalu merasa tidak nyaman dengan identitasnya. Kedua tokoh tidak diterima karena berbeda.

Kedua, intoleransi terjadi karena golongan mayoritas merasa unggul dan jawara dibandingkan dengan Sang Liyan. Cerpen Kate Chopin, seperti cerpen karya Liu menggambarkan adanya supremasi kulit putih. Obsesi pada warna kulit membuat Armand Aubigny tidak menyadari bahwa dalam tubuhnya mengalir darah ras berwarna kulit gelap yang selalu diremehkannya. Sebaliknya, tokoh Jack meremehkan dirinya sendiri yang berdarah campuran dan berusaha keras merangkul budaya Amerika yang menurut anggapannya lebih unggul dan berterima dalam masyarakat.

Ketiga, cerpen-cerpen yang dikaji muncul dari kerangka sosial yang rekat dan konsisten pada dominasi rasial dan penindasan atas perempuan dan kaum 
minoritas. Walaupun dimensi ras dan gender ini berbeda antara satu cerpen dengan yang lainnya, terbukti perempuan digambarkan sebagai pihak yang dikalahkan. Meskipun demikian, perempuan terkalahkan di setiap cerpen justru memiliki kepribadian yang terpuji. Elizabeth tetap setia dan merawat Pendeta Hooper hingga akhir hayat. Désirée berani meninggalkan suami dan segala kemewahan ketimbang hidup dengan suasana penuh kecurigaan atas asal-usulnya. Abai akan penyakitnya, ibu Jack terus berusaha merangkul budaya Amerika demi anak tunggalnya meskipun memperoleh penolakan yang luar biasa. Ketika sejarah resmi tidak atau jarang mencatat perjuangan perempuan, kehadiran perempuan-perempuan tangguh dalam ketiga cerpen yang dikaji dalam penelitian ini dapat memberikan sudut pandang yang baru.

Akhirnya, dalam kaitannya dengan pembelajaran Sejarah Amerika, cerpen-cerpen ini membuat pelbagai peristiwa sejarah menjadi lebih hidup dan manusiawi. Karya sastra selalu membantu menambah alur sejarah sehingga dapat menumbuhkan daya kritis dan empati pembelajar. Pelbagai peristiwa penting yang terekam secara sastrawi menjadi mudah diingat dan menarik untuk dipelajari serta memberikan makna mendalam bagi pembelajar.

\section{Daftar Rujukan}

Amboro, K. (2020). Kontekstualisasi Pandemi Covid-19 dalam Pembelajaran Sejarah. Yupa: Historical Studies Journal.

Awang, M. M., Ahmad, A. R., \& Talib, N. S. A. (2016). Penggunaan Multimedia Dalam Pendidikan Sejarah Pada Abad Ke-21 dan Hubungannya Dengan Minat Belajar Sejarah. Jurnal Pemikir Pendidikan, 7(5), 44-56.

Chopin, K. (2014). Désirée's Baby. . The Project Gutenberg EBook of Bayou Folk.

Clark, A. (2004). History teaching, historiography, and the politics of pedagogy in Australia. Theory \& Research in Social Education, 32(3), 379-396.

Cook, M. R. (2016). Counter-narratives of slavery in the Deep South: the politics of empathy along and beyond River Road. Journal of Heritage Tourism, 11(3), 290-308.

Davis, A. M. (2014). Apologies, Reparations, and the Continuing Legacy of the European Slave Trade in the United States. Journal of Black Studies, 45(4), 271-286.

Dervin, F., \& Jacobsson, A. (2021). Reflecting on Interculturality Through Critical and Reflexive Languaging. In Teacher Education for Critical and Reflexive Interculturality (pp. 99-116). Springer. 
Dewi, N. (2013). WOMEN OF WILL FOR NATION BUILDING IN PRAMOEDYA'S THREE EARLY NOVELS. Kritika Kultura, 20.

Einhaus, A.-M. (2016). Cultural memory, teaching and contemporary writing about the First World War. Literature E History, 25(2), 187-204.

Gavins, R. (2016). The Cambridge Guide to African American History. Cambridge University Press.

George, M. W. (2008). The elements of library research: What every student needs to know. Princeton University Press.

Gonzalez, J. (2017). Delving into Multicultural Literature with Inquiry.

Hamm, T. (2016). Quakers and Puritans review article. Reviews in History.

Hawthorne, N. (2004). The Minister's Black Veil.

Hirsch, A. R., \& Bell, C. C. (1998). Revolution, Romanticism, and the AfroCreole Protest Tradition in. The William and Mary Quarterly, 55(2).

Hower, J. S. (2019). 'All good stories': historical fiction in pedagogy, theory, and scholarship. Rethinking History, 23(1), 78-125.

Huckin, T. (2004). Content analysis: What texts talk about. In. C. Bazerman $\mathcal{E} P$. Prior (Eds.). What writing does and how it does it: An introduction to analyzing texts and textual practices (pp. 13-32). Mahwah, NJ: Lawrence Erlbaum Associates.

Ibrahim, N. (2018). Pemanfaatan Museum sebagai Sumber Belajar dalam Pembelajaran Sejarah. Visipena, 9(2), 215-235.

Kang, N. (2009). Puritanism and its impact upon American values. Rev. Eur. Stud., 1, 148.

Kaplan, H. (2018). Democratic humanism and American literature. In Democratic Humanism and American Literature. New York Routledge.

Kartodirdjo, S. (1989). Fungsi pengajaran sejarah dalam pembangunan nasional. dalam Historika. Surakarta UNS.

Kopley, R. (2012). Naysayers: Poe, Hawthorne, and Melville. In The Oxford Handbook of Transcendentalism.

Kurniawan, G. F. (2020). Problematika Pembelajaran Sejarah dengan Sistem Daring. Diakronika, 20(2).

Kurniawan, Ganda Febri. (2019). Pembelajaran Sejarah di Kelas XI SMA Semesta Bilingual Boarding School Semarang. Historia Pedagogia, 8(1), 6875.

Leise, C. (2017). The story upon a hill: The puritan myth in contemporary American Fiction. University of Alabama Press.

Liu, K. (2011). The Paper Menagerie. In The Paper Menagerie and Other Stories. Saga Press.

Luzer, D. (2013). The Protestant Work Ethic Is Real. Pacific Standard, 2-5.

Muse, C. (2014). The Dark Side of Human Natureq. Kentucky English Bulletin.

Nu'man, D. (1988). Nahdlatul Wathan Organisasi Pendidikan, Sosial dan Dakwah Islamiyah. Pengurus Daerah Nahdlatu Wathan.

Packer, J. I. (1994). Theology on fire. Christian History, 13(1), 32-35.

Paul, R., \& Elder, L. (2004). Critical Thinking... and the Art of Close Reading, Part III. Journal of Developmental Education, 28(1), 36-37.

Pestana, C. G. (1993). The Quaker executions as myth and history. The Journal of 
American History, 80(2), 441-469.

Printina, B. I. (2017). Penggunaan sumber belajar digital exelsa moodle dan komik toondo dalam meningkatkan kreativitas belajar sejarah. Agastya: Jurnal Sejarah Dan Pembelajarannya, 7(2), 57-67.

Putra, I. E. (2014). Teknologi media pembelajaran sejarah melalui pemanfaatan multimedia animasi interaktif. Jurnal Teknoif, 1(2).

Quong, S. B. (2019). Twin Text In The Secondary Social Studies And English Classroom.

Ririmasse, M. N. R. (2017). Sebelum Jalur Rempah: Awal Interaksi Niaga Lintas Batas di Maluku dalam Perspektif Arkeologi. Kapata Arkeologi, 13(1), 47-54.

Ryken, L. (2011). Worldly Saints: The Puritans as They Really Were-Work. Journal of Biblical Integration in Business, 13(1).

Sanchez, T. R., \& Mills, R. K. (2005). “ Telling tales": the teaching of American history through storytelling. Social Education, 69(5), 269.

Sardiman, S. (2017). Reformulasi Pembelajaran Sejarah: Sebuah Tantangan. ISTORIA: Jurnal Pendidikan Dan Sejarah, 13(1).

Senen, A., \& Barnadib, I. (2000). Tantangan guru sejarah: pesan sejarah sebagai konsep pendidikan nilai. Jurnal Penelitian Dan Evaluasi Pendidikan, 2(3).

Sohn, S. H. (2019). Defining and Exploring Asian American Speculative Fiction. In Oxford Research Encyclopedia of Literature.

Song, H. (2013). Chinese science fiction: a response to modernization. Science Fiction Studies, 40(1), 15-21.

Stambuk, A. (1999). Learning to hover: Robert Frost, Robert Francis, and the poetry of detached engagement. Twentieth Century Literature, 45(4), 534552.

Stoddard, J. D. (2012). Film as a 'thoughtful'medium for teaching history. Learning, Media and Technology, 37(3), 271-288.

Strong, T. (2017). Hawthorne, the politics of sin and puritanism. Telos, 2017(178), 121-142.

Thornton, S., \& Cruz, B. (2013). Teaching social studies to English language learners. Routledge.

Ufie, A. (2013). Kearifan lokal (local wisdom) budaya Ain Ni Ain masyarakat Kei sebagai sumber belajar sejarah lokal untuk memperkokoh kohesi sosial siswa. Universitas Pendidikan Indonesia.

VanSledright, B. A., \& Kelly, C. (1998). Reading American history: The influence of multiple sources on six fifth graders. The Elementary School Journal, 98(3), 239-265.

Widja, I. G. (2018). Pembelajaran Sejarah yang Mencerdaskan. Jurnal Pendidikan Sejarah Indonesia, 1(2), 117-134.

Yakushko, O., \& Rajan, I. (2017). Global love for sale: Divergence and convergence of human trafficking with "mail order brides" and international arranged marriage phenomena. Women $\mathcal{E}$ Therapy, 40(1-2), 190-206.

Youngs, S. (2012). Understanding history through the visual images in historical fiction. Language Arts, 89(6), 379-395.

Zollinger, H. (1851). Verslag van eene reis naar Bima en Soembawa, en naar eenige 
Sumini Theresia, Novita Dewi

Analisis Cerpen untuk Pembelajaran Sejarah Amerika

plaatsen op Celebes, Saleijer en Floris, gedurende de maanden Mei tot December 1847. Bataviaasch Genootschap van Kunsten en Wetenschappen, Lange. ZS, I. S. (2003). Penyair Lampung sebagai Warga sastra Indonesia.

Zubaidah, S. (2010). Berpikir Kritis : Kemampuan Berpikir Tingkat Tinggi (Issue 2009). 